\title{
Targeting adenosine receptor 2B in triple negative breast cancer
}

\author{
Carola A. Neumann ${ }^{1,2}$, Kevin Levine ${ }^{1,2}$, Steffi Oesterreich ${ }^{1,2}$ \\ 'Department of Pharmacology \& Chemical Biology, University of Pittsburgh Medical Center Hillman Cancer Center, Womens Cancer \\ Research \\ Center, Magee Womens Research Institute, Pittsburgh, PA 15213, USA. \\ ${ }^{2}$ Department of Pathology, University of Pittsburgh, Pittsburgh, PA 15261, USA.
}

Correspondence to: Dr. Carola A. Neumann, Department of Pharmacology \& Chemical Biology, University of Pittsburgh Medical Center Hillman Cancer Center, Womens Cancer Research Center, Magee Womens Research Institute, 204 Craft Ave, Pittsburgh, PA 15213, USA. E-mail: neumannc@upmc.edu How to cite this article: Neumann CA, Levine K, Oesterreich S. Targeting adenosine receptor 2B in triple negative breast cancer. J
Cancer Metastasis Treat 2018;4:13. http://dx.doi.org/10.20517/2394-4722.2017.60

Received: 26 Oct 2017 First Decision: 29 Dec 2017 Revised: 8 Mar 2018 Accepted: 8 Mar 2018 Published: 15 Mar 2018

Science Editor: William P. Schiemann Copy Editor: Jun-Yao Li Production Editor: Huan-Liang Wu

In the review "Role of adenosine in tumor progression: focus on $\mathrm{A} 2 \mathrm{~B}$ receptor as potential therapeutic target", Sorrentino and Morello make a compelling case for considering adenosine $2 \mathrm{~B}$ receptor (A2BR) as a target in cancer therapy (J Cancer Metastasis Treat 2017;3:127-38). A large body of evidence has accumulated suggesting A2BR to play an active role in tumor immune suppression and metastasis. Thus, this commentary will discuss the intriguing possibility of targeting A2BR in specific breast cancers that express high levels of $\mathrm{A} 2 \mathrm{BR}$ and attract infiltrating immune cells.

\section{TRIPLE NEGATIVE BREAST CANCER IS SUSCEPTIVE TO IMMUNE MODULATION}

Triple negative breast cancer (TNBC) is an aggressive subtype of breast cancer that disproportionally affects younger women and those of African origins, compared with Caucasians ${ }^{[1,2]}$. TNBC is devoid of the three receptors that classify and define most mammary cancers: estrogen receptor (ER), progesterone receptor (PR) and human epidermal growth factor receptor $2(\mathrm{HER} 2)^{[3]}$. The lack of these receptors reduces the efficacy of targeted therapies for this cancer type, limiting treatment options to chemotherapeutic agents, ionizing radiation and surgery. TNBC patients are therefore in dire need for novel targeted therapies.

Breast cancer has long been thought of as a non-immunogenic malignancy. However, a growing body of evidence suggests that this is not the case for all breast cancers. Tumor-infiltrating lymphocytes (TILs) are the most widely studied immune cells and include T cells and B cells. TILs are part of a larger category of infiltrating immune cells that include natural killer (NK) cells, macrophages, neutrophils, dendritic cells,

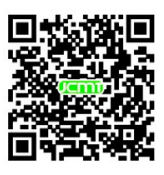


mast cells and other white blood cells. In breast cancer, TILs play an important role in mediating positive responses to chemotherapy and improving clinical outcomes. Specifically, in patients with HER2-positive breast cancer and TNBC, large adjuvant studies have shown that higher levels of TILs in primary biopsies were associated with prolonged overall survival (OS) and fewer recurrences, independent of therapy ${ }^{[4-6]}$. Similar results were also obtained in patient cohorts treated with neoadjuvant therapy. Here, increased levels of TILs in primary biopsies correlated with a higher pathological response rate $(\mathrm{pCR})^{[7-9]}$. On the other hand, tumor-associated macrophages (TAMs) that derive from peripheral blood monocytes are recruited to the TNBC tumor microenvironment and undergo activation that leads to the secretion of inhibitory cytokines, the reduction of effector functions of TILs and the promotion of regulatory $\mathrm{T}$ cells $(\text { Treg })^{[10]}$. High levels of TAMs are associated with distant metastasis in TNBC in humans and can be blocked by targeting the chemokine ligand 5 (CCL5) in a mouse model ${ }^{[11,12]}$. A growing body of evidence suggests that tumor-infiltrated immune cells from myeloid origin (myeloid-derived suppressor cells, MDSCs) differentiate into cells that promote tumor progression and metastasis in addition to their immunosuppressive role ${ }^{[13,14]}$. In a TNBC mouse model it was demonstrated that while monocytic ( $m$ )MDSCs infiltrated primarily the primary tumor, granulocytic $(g)$ MDSCs homed to metastases in the lung ${ }^{[15]}$. In humans, $g$ MDSCs were found to increase with neoadjuvant breast cancer therapies in patients showing no pathologic responses ${ }^{[16]}$. Collectively, this suggests that a group of TNBC can benefit from targeted immunotherapies. How can this TNBC patient cohort be identified?

TNBC is a heterogeneous breast cancer. Based on 3247 gene expression profiles, 21 breast cancer data sets have been analyzed that resulted in subtyping of TNBC which has been proven useful to decipher responses of TNBC patients to neoadjuvant therapies ${ }^{[17,18]}$. For example, patients in the basal-like 1 (BL 1) subgroup showed the highest pathological complete response of $41 \%$ compared to the basal-like 2 $(\mathrm{BL} 2)$ and the luminal androgen receptor (LAR) subgroup, $18 \%$ and $29 \%$, respectively ${ }^{[1718]}$. In addition, classifying then a TNBC cohort (587 patients) in three groups based on the amount of immune cell infiltration in the tumor, allowed to examine an immune signature comprising B- and T-cell markers that include immune-suppressive as well as immune-activating genes in these TNBC subtypes. This analysis revealed that out of all 587 TNBC cases, the ones correlating highest with the immune signature, were found mostly in the BL1 subtype. Interestingly, the M subgroup showed a strong negative correlation (Spearman, $-0.95)^{[17]}$. As the BL1 subtype is characterized by elevated cell cycle and DNA response genes, it may that the higher mutation rate of this TNBC subtype causes aberrant proteins expression that in turn attracts immune infiltrates. In aggregate, this suggests that TNBC patients subtyping by gene expression studies in conjunction with histopathological tissue analyses should be useful for selecting patient cohorts benefitting from immunotherapy.

\section{ADENOSINE RECEPTOR 2B EXPRESSION PLAYS AN IMPORTANT ROLE IN THE TUMOR MICROENVIRONMENT}

Four subtypes of G-protein - coupled adenosine receptors exist, designated Adora1 (A1R), Adora2a, (A2AR), Adora2b (A2BR), or Adora3 (A3R), and are classified according to utilization of pertussis toxin - sensitive (A1 and $\mathrm{A} 3$ ) or - insensitive (A2A and $\mathrm{A} 2 \mathrm{~B})$ pathways ${ }^{[19]}$. In the tumor microenvironment, many cell types express $\mathrm{A} 2 \mathrm{BR}$, especially under hypoxic conditions [Figure 1] ${ }^{[20]}$. In neutrophils $\mathrm{A} 1 \mathrm{R}$ has a higher affinity for adenosine compared to $\mathrm{A} 2 \mathrm{AR}$ or $\mathrm{A} 2 \mathrm{BR}$, and therefore at earlier stages of inflammation, lower local concentrations of adenosine promoted neutrophil recruitment, while later high concentrations of adenosine limit neutrophil recruitment through action of $\mathrm{A} 2 \mathrm{AR}$ or $\mathrm{A}_{2} \mathrm{BR}^{[21]}$. In dendritic cells (DCs), although other adenosine receptors are expressed, $\mathrm{A} 2 \mathrm{BR}$ mediates the differentiation of DCs that behave unlike myeloid DCs as they display impaired allostimulatory activity and express high levels of angiogenic, proinflammatory, immune suppressor and tolerogenic factors, including VEGF, IL-8, IL-6, IL-10, COX-2, TGF- $\beta$ and IDO. Furthermore, A2BR-mediated differentiation of DCs promoted lung tumors in mice ${ }^{[22]}$. Human 


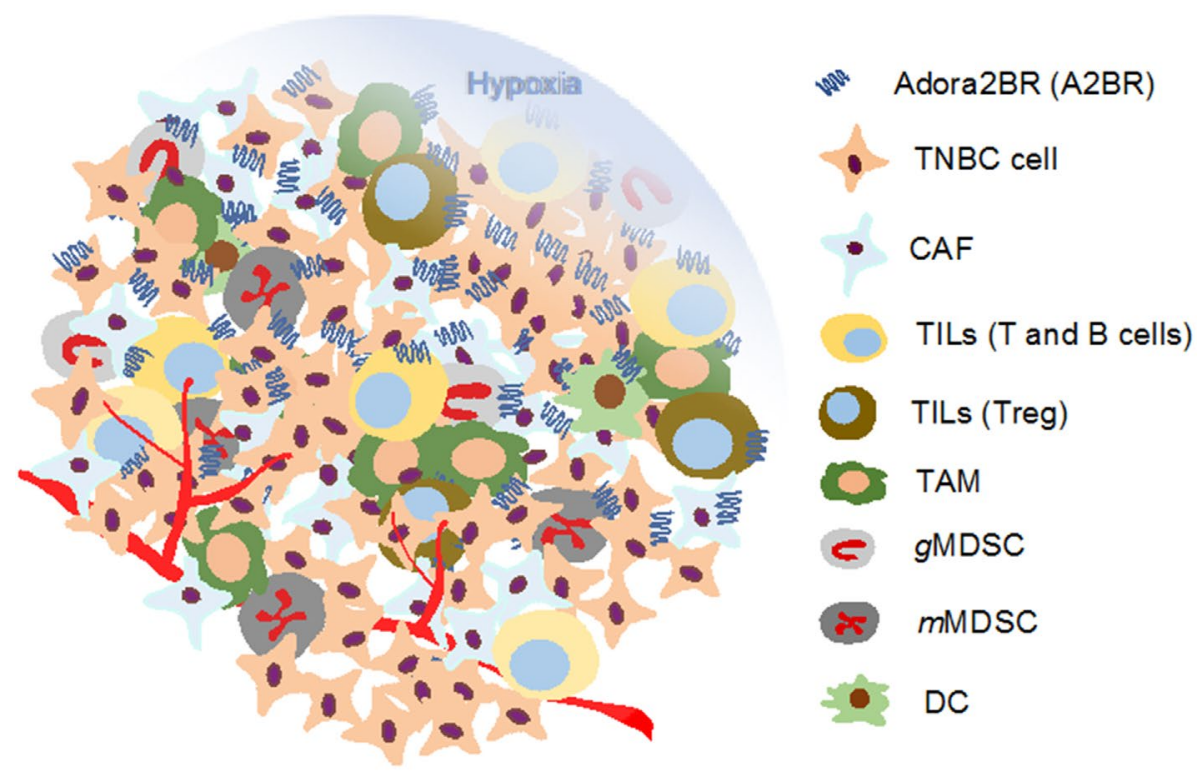

Figure 1. Expression of $A 2 B R$ on cells in the tumor microenvironment. The tumor microenvironment is very heterogeneous. Besides cancer cells, cancer-associated fibroblasts (CAFs), many different immune cells can infiltrate a tumor, such as tumor infiltrating lymphocytes (TILs), tumor associated macrophages (TAMs), granulocytic and monocytic myeloid-derived suppressor cells ( $g$ and $m$ MDSCs) and dentritic cells (DCs). While current studies suggest that in TNBC numbers of TILs positively correlate with good patient outcome, TAMs and MDSC do not

$\mathrm{T}$ cells predominantly express $\mathrm{A} 2 \mathrm{AR}$ and $\mathrm{A} 2 \mathrm{BR}$, in addtion to $\mathrm{A} 1$ and $\mathrm{A} 3$ receptors. The cAMP-elevating signaling through $\mathrm{A} 2 \mathrm{AR}$ or $\mathrm{A} 2 \mathrm{BR}$ in $\mathrm{T}$ cells results in inhibition of $\mathrm{T}$-cell receptor-triggered activation of $\mathrm{T}$ cells and of many effector functions, including proliferation, expansion and secretion by $\mathrm{T}$ cells of important anti-tumor cytokines such as IFN- $\gamma$ and TNF- $\alpha^{[23]}$. Studies in Adoraz $b^{-/}$mice revealed that lack of A2BR critically diminished regulatory T-cell (Treg) populations, underscoring the important role of A2BR in T-cell differentiation $^{[24]}$. A2AR as well as A2BR are also expressed on macrophages. Similarly, as found in DCs or T-cells, only A2BR plays a predominant role in the adenosine-dependent differentiation of macrophages. Once activated, macrophages express T-cell suppressing arginase, indoleamine-2,3-dioxygenase and TGF- $\beta$ and display reduced $\mathrm{T}$ cell stimulation which promotes tumor progression ${ }^{[25]}$. The adenosine binding to A2BR results in expansion of the MDSCs pool in tumors and accelerated tumor growth in mice ${ }^{[26]}$. MDSCsexpressing $\mathrm{A} 2 \mathrm{BR}$ have been successfully targeted with anti-A2BR therapy, suggesting that TNBC patients may benefit from such therapy as well, because they promote TNBC progression ${ }^{[15,16]}$. In mouse models pharmacological blockade of A2BR reduces tumor burden by activating DCs and improving CXCR3dependent $\mathrm{T}$ cell tumor infiltration in bladder and breast cancer ${ }^{[27,28]}$. Extensive work in mouse melanoma models has demonstrated that pharmacological A2BR blockade in combination with dacarbazine reduced tumor growth and significantly increased the number of $\mathrm{CD} 8^{+} \mathrm{T}$-cells decreases the number of cancer associated fibroblasts this way contributing to decreased melanoma tumor burden ${ }^{[26,29]}$. In summary, A2BR is an abundant protein in the tumor microenviroment.

\section{ADENOSINE RECEPTOR 2B FUNCTIONING IN TNBC}

In breast cancer $\mathrm{A} 2 \mathrm{AR}$ and $\mathrm{A} 2 \mathrm{BR}$ expression varies significantly among breast cancer subtypes. For example, while A2AR expression levels seem similarly expressed among Pam50 subtypes within the METABRIC data set (Molecular Taxonomy of Breast Cancer International Consortium), A2BR expression is significantly higher in basal cancers compared to the other subtypes, such as Her2, LumA and LumB [Figure 2] ${ }^{[30]}$. Expression patterns were confirmed in TCGA (The Cancer Genome Atlas) as well (data not shown; http://cancergenome.nih.gov). Comparing survival among breast cancer patients defined by the Pam50 gene expression, showed that basal-like breast cancers with higher A2BR expression showed shorter 
Table 1. Comparison of AR2A and AR2B expression and survival in basal like breast cancers

\begin{tabular}{lcccccc}
\hline & $\begin{array}{c}\text { OS log rank } \\
\boldsymbol{P} \text {-value }\end{array}$ & $\begin{array}{c}\text { Median OS } \\
\text { low/high } \\
\text { expression }\end{array}$ & Hazard ratio & $\begin{array}{c}\text { DMFS } \\
\text { Log rank } \\
\boldsymbol{P} \text {-value }\end{array}$ & $\begin{array}{c}\text { Median DMFS } \\
\text { low/high } \\
\text { expression }\end{array}$ & Hazard ratio \\
\hline AR2A & 0.012 & $40.8 / 97.5$ & $0.52(0.31-0.87)$ & 0.0008 & $18 / 97.5$ & $0.42(0.25-0.71)$ \\
AR2B & 0.011 & $95.1 / 41$ & $1.96(1.15-3.32)$ & 0.0004 & $102.6 / 23$ & $2.16(1.127-3.67)$ \\
\hline
\end{tabular}

Overall survival (OS) and distant metastasis free survival (DMSF) were compared and median survival calculated using km plotter. For OS 241 patients and for DMFS 242 patients were analyzed

A

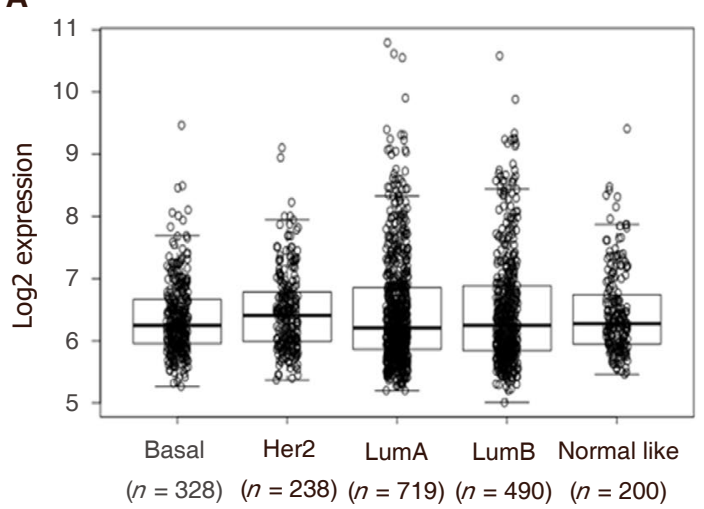

B

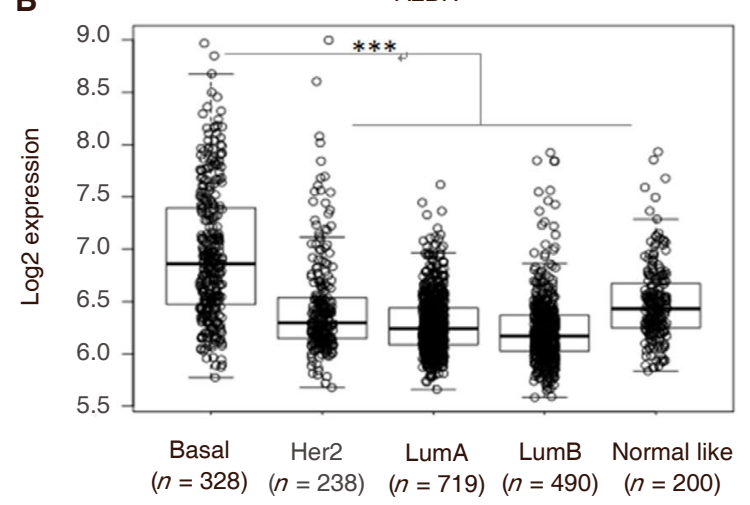

Figure 2. Comparison of $A 2 A R(A)$ and $A 2 B R(B)$ expression among Pam50 breast cancer subtypes in the METABRIC. A2BR is significantly higher expressed in basal like breast cancer compared to other breast cancer subtypes ( $\left.{ }^{\star \star \star} P=3.9 \mathrm{e}-11\right)$. Gene expression data from The Cancer Genome Atlas (TCGA) and Molecular Taxonomy of Breast Cancer International Consortium (METABRIC) were downloaded from the Gene expression Omnibus database [GEO: GSE62944] and Synapse software platform (syn1688369; Sage Bionetworks, Seattle, WA, USA), respectively

OS and distant metastasis free survival (DMFS) with a median survival for high expressors of 41 and 23 months, respectively. However, patients that expressed high levels of A2BR had a median OS of 95.1 months and a DMFS of 102.6 months, respectively [Table 1]. This is in contrast to high A2AR expression which seems to prolong overall survival in the basal breast cancer group [Table 1]. All in all, these findings suggest a functional difference between these two receptors in basal-like breast cancer. The term basal-like breast cancer is often used as a surrogate for identifying the aggressive TNBC subtype. Close to $80 \%$ of the basal like breast cancers are TNBC ${ }^{[31]}$. As TNBC is defined by lacking ER, PR and HER2, the basal subtype, is characterized by a distinct gene expression signature comprising strong expression of basal markers such as cytokeratins 5,6 and $17^{[32]}$.

Evidence already exists that blocking adenosine signaling may be a valuable option in treating TNBC. The A2BR ligand adenosine is produced in sequential action of CD39 and CD73 degrading ATP. Both are surface receptors expressed on cancer cells and like A2BR, induced by oxygen deprivation (hypoxia). In contrast to CD-39, CD73, also known as 5'-nucleotidase, is similar to A2BR, higher expressed in the ER-negative breast cancer population compared to the ER-positive cancers (METABRIC data base; $P=3.6 \mathrm{e}-14)$. This suggests a close co-operation of the two receptors in TNBC progression. In fact, mouse models have clearly demonstrated that CD73 expression promotes resistance to TNBC to anthracyclins and poor prognosis ${ }^{[33]}$. This has now been confirmed in human patients as data from the BIG-02-98 study conclude that high levels of CD73 expression on epithelial tumor cells positively associates with reduced DMFS and OS and negatively correlates with tumor immune cell infiltration (Spearman's $r=-0.50, P<0.0001$ ). Patients with high levels of CD73 and low levels of tumorinfiltrating leukocytes had the worse clinical outcome ${ }^{[34]}$. This suggests that adenosine signaling in $\mathrm{TNBC}$ associates with poor patient survival and that targeting CD73 or A2BR may provide a 
promising immunotherapeutic option for a group of TNBC patients. Regulatory T-cell depletion has been recently been shown to potentiate the inhibition of the immune checkpoint in claudin-low breast cancers, a subgroup of breast cancer that is largely found within the TNBC group of patients ${ }^{[35]}$.

Besides suppressing immune responses in TNBC, some studies suggest a A2BR immune independent function in breast cancer progression. For example, adenosine stimulates proliferation and migration of human TNBC cells through A2BR-mediated stimulation of adenylyl cyclase/PKA and a PLC-dependent $\mathrm{Ca}(2+)$ signal $^{[36,37]}$. Selective pharmacological activation of A2BR promoted tumor cell chemotaxis in vitro and metastasis in vivo using a syngeneic TNBC mouse model (4T1.2 cells). In contrast, the A2BR antagonist PSB1115 reversed significantly both phenotypes. As 4T1.2 cells express exclusively A2BR, the authors concluded that expression on A2BR on cancer cells contributes to breast cancer metastasis ${ }^{[38]}$. Mittal et al. ${ }^{[39]}$ confirmed these findings by showing that inhibition of $\mathrm{A} 2 \mathrm{RB}$ in vivo, using the $4 \mathrm{~T} 1.2$ mouse model was independent of $\mathrm{CD}_{4}{ }^{+}$or $\mathrm{CD} 8{ }^{+}$T-cells and/or natural killer cells in this setting. A synthetic lethality screen identified a pharmacological axis that identifies A2BR as a target gene of the transcription factor Fosrelated antigen-1 that promotes TNBC metastasis. In this model, both RNAi silencing and pharmacological inhibition of A2BR inhibited filapodia formation and invasive activity of TNBC cells and correspondingly reduced tumor outgrowth in the lungs in an immune-compromised mouse model ${ }^{[40]}$.

\section{FUTURE DIRECTIONS}

Tumor hypoxia is an unavoidable byproduct of fast and aggressive growing tumors, and the hypoxic response is quite robust in TNBC compared to other subtypes ${ }^{[41]}$. Deprivation of oxygen induces the accumulation of extracellular adenosine in tumors providing abundant ligand for adenosine receptors, such as $\mathrm{A} 2 \mathrm{BR}^{[25]}$. A2BR expression is higher in basal-like breast cancers compared to other breast cancer subtypes [Figure 2] and $\mathrm{A} 2 \mathrm{BR}$ is a major player in immune suppression, metastasis and relapse in TNBC. Therefore, A2BR provides an attractive target for treating TNBC, for which currently no targeted therapies exist. In particular the combination of immune checkpoint inhibitors together with A2BR agonists should be considered as viable treatment option, as checkpoint inhibitors show promising results in phase $1 / 2$ clinical trials in $\mathrm{TNBC}^{[42]}$. Besides presenting a viable drug target, A2BR may also serve as a prognostic biomarker in TNBC. More studies need to be done to test this hypothesis. Not unlike in other drug targeting strategies, more research is necessary to develop molecular and pathological parameters upfront that define appropriate patient cohorts that should be tested for anti-A2BR therapies. For example, TNBC subtyping shows how heterogeneous TNBC subtypes are. In addition, analyses are necessary to determine A2BR antagonistic effects on TILs in TNBC and patient outcome. In summary, based on current research, A2BR may present a viable drug candidate in a defined cohort of TNBC breast patients.

\section{DECLARATIONS}

\section{Authors' contributions}

Wrote the manuscript: Neumann CA

Developed the METABRIC expression and analysis tool: Levine K, Oesterreich S

Financial support and sponsorship

None.

\section{Conflicts of interest}

There are no conflicts of interest.

\section{Patient consent}

Not applicable. 


\section{Ethics approval}

Not applicable.

\section{Copyright}

(c) The Author(s) 2018.

\section{REFERENCES}

1. Dietze EC, Sistrunk C, Miranda-Carboni G, O’Regan R, Seewaldt VL. Triple-negative breast cancer in African-American women: disparities versus biology. Nat Rev Cancer 2015;15:248-54.

2. Lindner R, Sullivan C, Offor O, Lezon-Geyda K, Halligan K, Fischbach N, Shah M, Bossuyt V, Schulz V, Tuck DP, Harris LN. Molecular phenotypes in triple negative breast cancer from African American patients suggest targets for therapy. PLoS One 2013;8:e71915.

3. Foulkes WD, Smith IE, Reis-Filho JS. Triple-negative breast cancer. N Engl J Med 2010;363:1938-48.

4. Loi S, Sirtaine N, Piette F, Salgado R, Viale G, Van Eenoo F, Rouas G, Francis P, Crown JP, Hitre E, de Azambuja E, Quinaux E, Di Leo A, Michiels S, Piccart MJ, Sotiriou C. Prognostic and predictive value of tumor-infiltrating lymphocytes in a phase III randomized adjuvant breast cancer trial in node-positive breast cancer comparing the addition of docetaxel to doxorubicin with doxorubicin-based chemotherapy: BIG 02-98. J Clin Oncol 2013;31:860-7.

5. Loi S, Michiels S, Salgado R, Sirtaine N, Jose V, Fumagalli D, Kellokumpu-Lehtinen PL, Bono P, Kataja V, Desmedt C, Piccart MJ, Loibl S, Denkert C, Smyth MJ, Joensuu H, Sotiriou C. Tumor infiltrating lymphocytes are prognostic in triple negative breast cancer and predictive for trastuzumab benefit in early breast cancer: results from the FinHER trial. Ann Oncol 2014;25:1544-50.

6. Salgado R, Denkert C, Campbell C, Savas P, Nuciforo P, Aura C, de Azambuja E, Eidtmann H, Ellis CE, Baselga J, Piccart-Gebhart MJ, Michiels S, Bradbury I, Sotiriou C, Loi S. Tumor-infiltrating lymphocytes and associations with pathological complete response and event-free survival in HER2-positive early-stage breast cancer treated with lapatinib and trastuzumab: a secondary analysis of the NeoALTTO Trial. JAMA Oncol 2015;1:448-54.

7. Denkert C, Loibl S, Noske A, Roller M, Muller BM, Komor M, Budczies J, Darb-Esfahani S, Kronenwett R, Hanusch C, von Torne C, Weichert W, Engels K, Solbach C, Schrader I, Dietel M, von Minckwitz G. Tumor-associated lymphocytes as an independent predictor of response to neoadjuvant chemotherapy in breast cancer. J Clin Oncol 2010;28:105-13.

8. Ono M, Tsuda H, Shimizu C, Yamamoto S, Shibata T, Yamamoto H, Hirata T, Yonemori K, Ando M, Tamura K, Katsumata N, Kinoshita T, Takiguchi Y, Tanzawa H, Fujiwara Y. Tumor-infiltrating lymphocytes are correlated with response to neoadjuvant chemotherapy in triplenegative breast cancer. Breast Cancer Res Treat 2012;132:793-805.

9. Denkert C, von Minckwitz G, Brase JC, Sinn BV, Gade S, Kronenwett R, Pfitzner BM, Salat C, Loi S, Schmitt WD, Schem C, Fisch K, Darb-Esfahani S, Mehta K, Sotiriou C, Wienert S, Klare P, Andre F, Klauschen F, Blohmer JU, Krappmann K, Schmidt M, Tesch H, Kummel S, Sinn P, Jackisch C, Dietel M, Reimer T, Untch M, Loibl S. Tumor-infiltrating lymphocytes and response to neoadjuvant chemotherapy with or without carboplatin in human epidermal growth factor receptor 2-positive and triple-negative primary breast cancers. J Clin Oncol 2015;33:983-91.

10. Santoni M, Romagnoli E, Saladino T, Foghini L, Guarino S, Capponi M, Giannini M, Cognigni PD, Ferrara G, Battelli N. Triple negative breast cancer: key role of tumor-associated macrophages in regulating the activity of anti-PD-1/PD-L1 agents. Biochim Biophys Acta 2018;1869:78-84.

11. Yuan ZY, Luo RZ, Peng RJ, Wang SS, Xue C. High infiltration of tumor-associated macrophages in triple-negative breast cancer is associated with a higher risk of distant metastasis. Oncol Targets Ther 2014;7:1475-80.

12. Frankenberger C, Rabe D, Bainer R, Sankarasharma D, Chada K, Krausz T, Gilad Y, Becker L, Rosner MR. Metastasis suppressors regulate the tumor microenvironment by blocking recruitment of prometastatic tumor-associated macrophages. Cancer Res 2015;75:406373.

13. Marvel D, Gabrilovich DI. Myeloid-derived suppressor cells in the tumor microenvironment: expect the unexpected. J Clin Invest 2015; 125:3356-64.

14. Condamine T, Ramachandran I, Youn JI, Gabrilovich DI. Regulation of tumor metastasis by myeloid-derived suppressor cells. Annu Rev Med 2015;66:97-110.

15. Ouzounova M, Lee E, Piranlioglu R, El Andaloussi A, Kolhe R, Demirci MF, Marasco D, Asm I, Chadli A, Hassan KA, Thangaraju M, Zhou G, Arbab AS, Cowell JK, Korkaya H. Monocytic and granulocytic myeloid derived suppressor cells differentially regulate spatiotemporal tumour plasticity during metastatic cascade. Nat Commun 2017;8:14979.

16. Wesolowski R, Duggan MC, Stiff A, Markowitz J, Trikha P, Levine KM, Schoenfield L, Abdel-Rasoul M, Layman R, Ramaswamy B, Macrae ER, Lustberg MB, Reinbolt RE, Mrozek E, Byrd JC, Caligiuri MA, Mace TA, Carson WE 3rd. Circulating myeloidderived suppressor cells increase in patients undergoing neo-adjuvant chemotherapy for breast cancer. Cancer Immunol Immunother 2017;66:1437-47.

17. Lehmann BD, Jovanovic B, Chen X, Estrada MV, Johnson KN, Shyr Y, Moses HL, Sanders ME, Pietenpol JA. Refinement of triplenegative breast cancer molecular subtypes: implications for neoadjuvant chemotherapy selection. PLoS One 2016;11:e0157368.

18. Lehmann BD, Bauer JA, Chen X, Sanders ME, Chakravarthy AB, Shyr Y, Pietenpol JA. Identification of human triple-negative breast cancer subtypes and preclinical models for selection of targeted therapies. J Clin Invest 2011;121:2750-67.

19. Linden J. Molecular approach to adenosine receptors: receptor-mediated mechanisms of tissue protection. Annu Rev Pharmacol Toxicol 2001;41:775-87. 
20. Koeppen M, Eckle T, Eltzschig HK. Interplay of hypoxia and A2B adenosine receptors in tissue protection. Adv Pharmacol 2011;61:14586.

21. Cronstein BN, Daguma L, Nichols D, Hutchison AJ, Williams M. The adenosine/neutrophil paradox resolved: human neutrophils possess both A1 and A2 receptors that promote chemotaxis and inhibit O2 generation, respectively. J Clin Invest 1990;85:1150-7.

22. Novitskiy SV, Ryzhov S, Zaynagetdinov R, Goldstein AE, Huang Y, Tikhomirov OY, Blackburn MR, Biaggioni I, Carbone DP, Feoktistov I, Dikov MM. Adenosine receptors in regulation of dendritic cell differentiation and function. Blood 2008;112:1822-31.

23. Lukashev D, Sitkovsky M, Ohta A. From "Hellstrom Paradox" to anti-adenosinergic cancer immunotherapy. Purinergic Signal 2007;3:129-34.

24. Ehrentraut H, Westrich JA, Eltzschig HK, Clambey ET. Adora2b adenosine receptor engagement enhances regulatory T cell abundance during endotoxin-induced pulmonary inflammation. PLoS One 2012;7:e32416.

25. Ohta A. A metabolic immune checkpoint: adenosine in tumor microenvironment. Front Immunol 2016;7:109.

26. Iannone R, Miele L, Maiolino P, Pinto A, Morello S. Blockade of A2b adenosine receptor reduces tumor growth and immune suppression mediated by myeloid-derived suppressor cells in a mouse model of melanoma. Neoplasia 2013;15:1400-9.

27. Young A, Ngiow SF, Barkauskas DS, Sult E, Hay C, Blake SJ, Huang Q, Liu J, Takeda K, Teng MWL, Sachsenmeier K, Smyth MJ. Coinhibition of CD73 and A2AR adenosine signaling improves anti-tumor immune responses. Cancer Cell 2016;30:391-403.

28. Leone RD, Lo YC, Powell JD. A2aR antagonists: next generation checkpoint blockade for cancer immunotherapy. Comput Struct Biotechnol J 2015;13:265-72.

29. Sorrentino C, Miele L, Porta A, Pinto A, Morello S. Activation of the A2B adenosine receptor in B16 melanomas induces CXCL12 expression in FAP-positive tumor stromal cells, enhancing tumor progression. Oncotarget 2016;7:64274-88.

30. Curtis C, Shah SP, Chin SF, Turashvili G, Rueda OM, Dunning MJ, Speed D, Lynch AG, Samarajiwa S, Yuan Y, Graf S, Ha G, Haffari G, Bashashati A, Russell R, McKinney S, Group M, Langerod A, Green A, Provenzano E, Wishart G, Pinder S, Watson P, Markowetz F, Murphy L, Ellis I, Purushotham A, Borresen-Dale AL, Brenton JD, Tavare S, Caldas C, Aparicio S. The genomic and transcriptomic architecture of 2,000 breast tumours reveals novel subgroups. Nature 2012;486:346-52.

31. Alluri P, Newman LA. Basal-like and triple-negative breast cancers: searching for positives among many negatives. Surg Oncol Clin N Am 2014;23:567-77.

32. Perou CM, Sorlie T, Eisen MB, van de Rijn M, Jeffrey SS, Rees CA, Pollack JR, Ross DT, Johnsen H, Akslen LA, Fluge O, Pergamenschikov A, Williams C, Zhu SX, Lonning PE, Borresen-Dale AL, Brown PO, Botstein D. Molecular portraits of human breast tumours. Nature 2000;406:747-52.

33. Loi S, Pommey S, Haibe-Kains B, Beavis PA, Darcy PK, Smyth MJ, Stagg J. CD73 promotes anthracycline resistance and poor prognosis in triple negative breast cancer. Proc Natl Acad Sci U S A 2013;110:11091-6.

34. Buisseret L, Pommey S, Allard B, Garaud S, Bergeron M, Cousineau I, Ameye L, Bareche Y, Paesmans M, Crown JPA, Di Leo A, Loi S, Piccart-Gebhart M, Willard-Gallo K, Sotiriou C, Stagg J. Clinical significance of CD73 in triple-negative breast cancer: multiplex analysis of a phase III clinical trial. Ann Oncol 2017; doi: 10.1093/annonc/mdx730.

35. Taylor NA, Vick SC, Iglesia MD, Brickey WJ, Midkiff BR, McKinnon KP, Reisdorf S, Anders CK, Carey LA, Parker JS, Perou CM, Vincent BG, Serody JS. Treg depletion potentiates checkpoint inhibition in claudin-low breast cancer. J Clin Invest 2017;127:3472-83.

36. Panjehpour M, Castro M, Klotz KN. Human breast cancer cell line MDA-MB-231 expresses endogenous A2B adenosine receptors mediating a Ca2+ signal. Br J Pharmacol 2005;145:211-8.

37. Fernandez-Gallardo M, Gonzalez-Ramirez R, Sandoval A, Felix R, Monjaraz E. Adenosine stimulate proliferation and migration in triple negative breast cancer cells. PLoS One 2016;11:e167445.

38. Stagg J, Divisekera U, McLaughlin N, Sharkey J, Pommey S, Denoyer D, Dwyer KM, Smyth MJ. Anti-CD73 antibody therapy inhibits breast tumor growth and metastasis. Proc Natl Acad Sci U S A 2010;107:1547-52.

39. Mittal D, Sinha D, Barkauskas D, Young A, Kalimutho M, Stannard K, Caramia F, Haibe-Kains B, Stagg J, Khanna KK, Loi S, Smyth MJ. Adenosine 2B receptor expression on cancer cells promotes metastasis. Cancer Res 2016;76:4372-82.

40. Desmet CJ, Gallenne T, Prieur A, Reyal F, Visser NL, Wittner BS, Smit MA, Geiger TR, Laoukili J, Iskit S, Rodenko B, Zwart W, Evers B, Horlings H, Ajouaou A, Zevenhoven J, van Vliet M, Ramaswamy S, Wessels LF, Peeper DS. Identification of a pharmacologically tractable Fra-1/ADORA2B axis promoting breast cancer metastasis. Proc Natl Acad Sci U S A 2013;110:5139-44.

41. Bernardi R, Gianni L. Hallmarks of triple negative breast cancer emerging at last? Cell Res 2014;24:904-5.

42. Pusztai L, Silber A, Hofstatter EW, Chung GG, Horowitz NR, Lannin DR, Killelea BK, Chagpar AB, Szekely B, Frederick C, Rispoli L, DiGiovanna M. Safety of MEDI4736 (anti-PD-L1 antibody) administered concomitant with weekly nab-paclitaxel and dose dense doxorubicin/cyclophosphamide (ddAC) as neoadjuvant chemotherapy for stage I-III triple negative breast cancer (TNBC): a phase I/II trial. J Clin Oncol 2017;35 Suppl 15:abstr572. 